priate to barium titanate where the field in which the ion moves is anharmonic. The former gives with temperature a rapid change of $\chi$, the reciprocal susceptibility or dielectric stiffness, while the latter gives a small change. Thus, the respective values of $\partial \chi / \partial T$ are $28 \cdot 0$ and $0 \cdot 75$. The Mason model for Rochelle salt was also considered. Here two sets of ions moving in unsymmetrical fields provide, as required for this material, a polar state stable only between two temperatures. A model for anti-ferroelectricity might be built on similar lines.

Both sessions were terminated by general discussions, Dr. Matthias presiding on the first day and C. G. Garton (Electrical Research Association) on the second. The subjects at both discussions were the practical uses of barium titanate crystals, with particular emphasis on digital storage. The fundamentals of storage and methods of investigation were described. Dr. Matthias said that the Bell Laboratories are concentrating on investigations into the serious deterioration in polarization properties caused by the protracted application of unbalanced pulse trains. Mr. Oxbrow said the deterioration is amplitude-dependent and is serious only if pulse amplitudes of the order of the coercive field are used. I. Carter (Ferranti, Ltd.) reported that, after the decay, a low-frequency property, sufficient storage effect exists for high-speed operation. Also, the initial state can be restored by periodic application of a small d.c. bias. Dr. A. Robinson (Ferranti, Ltd.) compared the merits of dielectric and ferrite storage. The advantages of barium titanate storage are compactness and a more convenient impedance for use in valve circuitry. Ferrite storage has the advantages of a more advanced state of development and, although offset by elumsiness, the versatility of variable 'turns-ratio' coupling. Very recent experiments with barium titanate indicate polarization times as low as $0.5 \mu \mathrm{sec}$., so that it might permit greater speeds of operation than ferrite.

A. C. Lynch (General Post Office) said that confirmation by Merz ${ }^{1}$ that $180^{\circ}$ walls do not move laterally has removed the fear that the polarizations of adjacent crystal areas might interfere. B. de Ferranti (General Electric Co., Itd.) suggested that the non-linear characteristic of barium titanate capacitance versus field should be used in a dielectric amplifier. This would necessitate further investigation of noise in ceramics and single erystals. I. Ross (Services Electronics Research Laboratory) mentioned a possible use in infra-red switching, provided that the change in the $45^{\circ}$ laminar domains is adequately fast. Measurements have been made of the infra-red transmission of one of the Bell crystals. C. F. OxBrow

${ }^{2}$ Merz, W. J., Phys. Rev., 95, 690 (1954).

a Remeika, J. P., J. Amer. Chem. Soc., 78, 940 (1954).

\section{SHIFT WORK IN INDUSTRY}

$\mathrm{T}$

HE Institute of Persorinel Management (2-10 Hill Strect, London, W.1) has issued a broadsheet surveying the issues which affect the application of shift systems in industry. The broadsheet has been prepared by F. P. Cook, of Courtaulds, Ltd., but is based upon information obtained from a large number of different industries.

Among the conclusions brought out in the survey is that the economic advantages of shift work are greatest where capital charges and overheads are high in relation to labour costs. The greater the proportion of the total cost of production that is occupied by labour costs, the less the economic advantages of shift work become. When shift work is first introduced in a discontinuous process where employment has previously been on day work, the double-day shift system is probably the most advantageous for all concerned-for management because it is a second shift which offers the greatest alleviation to fixed charges, and for employees because the physical and social disadvantages are much less than those of shift systems which involve night work. The appeal of shift work to employees depends largely on how attractive it is made financially. Although it is only one factor, shift work can prove a sound economic way of meeting the natural urge towards shorter hours of work and higher earnings.

Quite apart from the ballot which is usually required by law before women and young persons can be employed on double day-shift work, the investigations show that full explanation and consultation are needed before any successful shift system can be introduced. Of all shift systems, those involving night work are most likely to have a deleterious effect on health; this is especially applicable to systems which involve permanent night work. Any unfortunate effects will vary with individuals, the nature and hours of their work, and their habits outside the factory, so that it would be hard to establish a general rule, even if more evidence were available. For most employees, shift work involves a balancing of material gain against social loss ; thus, in pursuing the possible economic advantages of the extension of shift work, which can only be a gradual process, those in authority must take the possible social drawbacks into account.

Mr. Cook concludes that one of the temptations of these complicated times is to over-simplify, and this is typified by the search for the single solution to any problem. In personnel management, recent years have seen the fashionable development of joint consultation, job evaluation, communications, financial incentives, financial enlightenment, merit rating of management development, and work study. Despite the creation of much pseudo-technical supporting jargon, not one of these is a cure-all by itself, and together they can be no more than further aids to the vastly complicated business of modern industrial management. The extension of shift work will not alone revive the fortunes of a nation or concern; but, in the right circumstances, it can help.

\section{FORESTRY COMMISSION REPORT FOR THE YEAR 1952-53}

IN the operations of the Forestry Commission during the year $1952-53^{*}$, economy in spending was a guiding factor in deciding the programme of work. In order to carry out the expanding programme of planting and thinnings in the young plantations with the funds available, it was necessary to postpone work such as building new houses and new roads. Many of the forest services of the British.

* Forestry Commission. Thirty-fourth Annual Report of the Forestry Commissioners for the Year ended September 30th, 1953. Pp. 84. (London: H.M.S.O, 1954.) 3s. net. 